\title{
PROTEKSI RELE JARAK PADA JARINGAN SUTT 150 KV GI AMPENAN - PLTU LOMBOK ENERGY DYNAMIC (LED)
}

\section{Distance Relay Protection on High Voltage Transmission Line 150 kV From Ampenan Substation to Lombok Energy Dynamic Steam Power Plant}

\author{
Dwinanto Romdhani ${ }^{[1]}$, Supriyatna ${ }^{[2]}$, Agung Budi Muljono ${ }^{[2]}$ \\ [1]Jurusan Teknik Elektro, FT UNRAM, PT PLN Wilayah NTB. \\ ${ }^{[2]}$ Jurusan Teknik Elektro, Fakultas Teknik Universitas Mataram, Nusa Tenggara Barat. \\ Email :dwinanto.romdhani@gmail.com, supriyatna@unram.ac.id, agungbm@unram.ac.id
}

\begin{abstract}
ABSTRAK
Sistem kelistrikan Lombok telah mengoperasikan Pembangkit Listrik Tenaga Uap (PLTU) Lombok Energy Dynamic (LED). Energi listrik dari PLTU LED disalurkan melalui Saluran Udara Tegangan Tinggi $150 \mathrm{kV}$. Oleh karena itu, diperlukan proteksi yang baik untuk menjaga keandalan penyaluran energi listrik. Salah satu rele yang digunakan pada proteksi sistem kelistrikkan Lombok adalah rele jarak. Rele jarak bekerja sebagai pengaman utama pada saluran transmisi. Rele ini mengukur besar impedansi gangguan berdasarkan arus dan tegangan yang terdeteksi oleh rele. Penelitian ini menghitung setting impedansi rele jarak pada

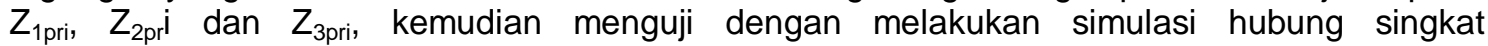
menggunakan software ETAP 12.6. Hasil perhitungan setting rele jarak di Gl Ampenan untuk memproteksi saluran Ampenan - Jeranjang impedansi saluran 3,25714 $\Omega(7,543 \mathrm{~km})$ adalah $Z_{1 \text { pri }}=2,6057 \Omega(6,034 \mathrm{~km}), \mathrm{t}_{1}=0$ detik; $Z_{2 \text { pri }}=3,9086 \Omega(9,0516 \mathrm{~km}), \mathrm{t}_{2}=0,4$ detik; $Z_{3 \text { pri }}=$ $22,5627 \Omega(52,25 \mathrm{~km}), \mathrm{t}_{3}=1,2$ detik. Impedansi setting rele lebih besar dari impedansi gangguan yang terdeteksi oleh rele sehingga rele jarak sudah dapat melindungi sistem. Hasil penelitian memperlihatkan grafik koordinasi impedansi dan waktu setting rele jarak pada masing-masing seksi zone proteksi.
\end{abstract}

Kata kunci: saluran udara tegangan tinggi $150 \mathrm{kV}$, rele jarak, koordinasi sistem proteksi, ETAP version 12.6.

\section{ABSTRACT}

Lombok electrical system has operated Steam Power Plant. Electrical energy from Lombok Energy Dynamic (LED) is transmited with a $150 \mathrm{kV}$ high voltage transmission line. Therefore, a good protection system is needed to maintain the distribution reliability of electrical power. One of the relays used in the Lombok electrical protection system is a distance relay. Distance relay works as the main protection in transmission system by measuring fault impedance value based on current and voltage detected by the relay. The purpose of this study was to calculate distance relay setting impedance in $Z_{1 \text { pri, }} Z_{2 \text { pri }}$ and $Z_{3 \text { pri }}$ then held a short-circuit simulation in software ETAP 12.6 to examine it. Setting calculation result of distance relay in Ampenan Substation for Ampenan - Jeranjang line protection, with $3,25714 \Omega(7.543 \mathrm{~km})$ line impedance, is $Z_{1 \text { pri }}=$ $2.6057 \Omega(6.034 \mathrm{~km}), t_{1}=0$ second, $Z_{2 \text { pri }}=3.9086 \Omega(9.0516 \mathrm{~km}), t_{2}=0.4$ second, $Z_{3 \text { ori }}=$ $22.5627 \Omega(52.25 \mathrm{~km}), t_{3}=1.2$ second. Relay's setting impedance is larger than fault impedance detected by the relay, so that distance relay has been able to protect the system. This study may also show a graphic of setting impedance and time coordination from distance relay for every protection area section.

Key words: High voltage transmission line $150 \mathrm{kV}$, distance relay, protection system coordination, ETAP version 12.6 .

\section{PENDAHULUAN}

Provinsi NTB merupakan daerah dengan tingkat pertumbuhan ekonomi serta pertumbuhan jumlah penduduk yang semakin meningkat. Peningkatan tersebut juga mengakibatkan permintaan kebutuhan pasokan listrik di Provinsi NTB terus meningkat. Untuk mengatasi masalah 
tersebut pemerintah melalui PLN (Perusahaan Listrik Negara) telah menambah jumlah kapasitas pembangkit di Lombok antara lain yaitu pusat Pembangkit Listrik Tenaga Uap (PLTU) Jeranjang kapasitas 2×25 MW, Mobile Power Plant (MPP) kapasitas 2x25 MW, dan pusat Pembangkit Listrik Tenaga Uap (PLTU) Lombok Energy Dinamic (LED) kapasitas 2x25 MW. Penambahan pembangkit tersebut diharapkan dapat menyediakan listrik yang berkualitas baik untuk industri, instansi pemerintah, pengembangan pariwisata, fasilitas umum dan masyarakat.

Sistem kelistrikan Lombok sampai saat ini telah beroperasi 8 Gardu Induk yang dihubungkan oleh saluran udara tegangan tinggi (SUTT). Pembangunan SUTT ini merupakan usaha dalam meningkatkan kualitas serta keandalan suatu sistem kelistrikan. Saluran transmisi udara seringkali mengalami gangguan yang mengakibatkan pemadaman. Gangguan yang terjadi baik berasal dari dalam sistem maupun luar sistem seperti gangguan hubung singkat, gangguan beban lebih, gangguan yang diakibatkan cuaca buruk. Gangguan tersebut dapat mengakibatkan kerusakan pada peralatan serta terganggunya proses penyaluran tenaga listrik. Untuk mencegah dan meminimalisir kerusakan akibat terjadinya gangguan tersebut, maka dibutuhkan suatu sistem proteksi yang andal dan baik. Sistem proteksi berfungsi untuk menjaga kestabilan proses penyaluran tenaga listrik dengan cara mendeteksi terjadinya ganguan atau keadaaan tidak wajar pada sistem kemudian memutus bagian sistem yang terganggu sehingga bagian yang tidak terganggu dapat terus beroperasi.

Rele jarak difungsikan sebagai pengaman utama pada saluran udara tegangan tinggi (SUTT) 150 kV sistem kelistrikan Lombok. Prinsip dasar rele jarak adalah membaca impedansi berdasarkan besaran arus dan tegangan yang dirasakan untuk menentukan apakah rele harus bekerja atau tidak. Agar dapat bekerja secara baik maka diperlukan koordinasi antar rele pada setiap section. Koordinasi rele jarak didasarkan pada parameter transmisi dengan memperhatikan parameter gangguan.

Untuk menunjang penyaluran energi listrik dari PLTU LED kapasitas 2x25 MW, maka dioperasikanlah saluran transmisi tegangan tinggi 150 kV dari Gardu Induk Pringgabaya menuju Gardu Induk PLTU LED pada sistem kelistrikan Lombok. Oleh karena itu, diperlukan penelitian mengenai koordinasi proteksi rele jarak pada SUTT $150 \mathrm{kV}$ sistem kelistrikan Lombok dengan beroperasinya PLTU LED 2x25 MW sehingga diharapkan proteksi tetap dapat bekerja secara cepat dan selektif.

\section{SistemTenaga Listrik.}

Sistem tenaga listrik adalah suatu sistem yang membangkitkan, mengatur, menyalurkan, mendistribusikan dan memanfaatkan tenaga listrik. Secara umum sistem ketenagalistrikan terdiri dari lima sistem utama yaitu pembangkit listrik, sistem transmisi, gardu induk, sistem distribusi dan beban.

Komponen-komponen utama dari transmisi jenis saluran udara terdiri dari :

1. Menara transmisi atau tiang transmisi beserta pondasinya

2. Isolator-isolator

3. Kawat penghantar

4. Kawat tanah

\section{Proteksi Sistem Tenaga Listrik.}

Proteksi sistem tenaga listrik adalah sistem proteksi yang dilakukan kepada peralatan-peralatan listrik yang terpasang pada suatu sistem tenaga terhadap kondisi abnormal pada sistem tenaga.

Fungsi Proteksi adalah memisahkan bagian sistem yang terganggu sehingga bagian sistem lainnya dapat tetap beroperasi, hal ini dilakukan dengan cara:

1. Mendeteksi adanya gangguan atau keadaan abnormal lainnya pada bagian sistem yang diamankannya (fault detection).

2. Memberikan indikasi adanya gangguan.

3. Melepaskan bagian sistem yang terganggu (fault clearing).

\section{Komponen-komponen Sistem Proteksi.}

Sistem proteksi tenaga listrik terdiri dari 4 (empat) komponen utama [1]:

1. Current Transformer (CT) dan / atau Potensial Transformer (PT)

2. Rele

3. Circuit Breaker (CB)

4. Baterai / power supply.

Syarat-syarat Umum Rele Proteksi.

Rele proteksi ditinjau dari jenis dan dalam penggunaannya harus memiliki syarat-syarat yang penting dalam pengoperasiannya sehingga dapat bekerja sesuai dengan fungsinya secara maksimal. Syarat tersebut terdiri dari beberapa hal yakni:

1. Kecepatan Kerja.

2. Sensitifitas (Kepekaan). 
3. Selektifitas.

4. Andal (Reliable).

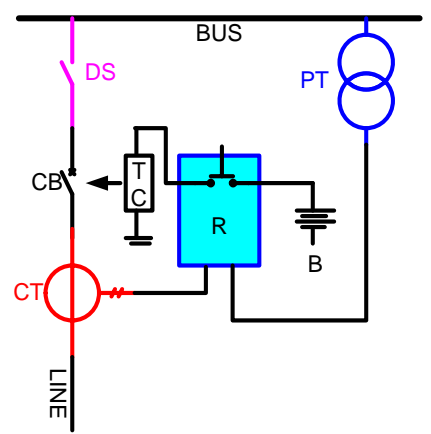

Gambar 1 Komponen sistem proteksi tenaga listrik.

Pola Proteksi Saluran Udara Tegangan Tinggi (SUTT). Sistem pengaman suatu peralatan karena berbagai macam faktor dapat mengalami kegagalan operasi (gagal operasi). Berdasarkan hal-hal tersebut maka suatu sistem proteksi dapat dibagi dalam dua kelompok [2], yaitu:

\section{Pengaman Utama}

Merupakan system proteksi yang diharapkan segera bekerja jika terjadi kondisi abnormal atau gangguan pada daerah pengamanannya.

\section{Pengaman Cadangan}

Diperlukan apabila pengaman utama tidak dapat bekerja atau terjadi gangguan padasistem pengaman utama itu sendiri.

\section{Rele Jarak.}

Rele Jarak merupakan salah satu jenis rele proteksi yang digunakan sebagai pengaman pada saluran transmisi karena kemampuannya dalam menghilangkan gangguan (fault clearing) dengan cepat dan penyetelannya yang relatif mudah. Pada prinsipnya, rele jarak adalah mengukur nilai arus dan nilai tegangan pada suatu titik tertentu sehingga diperoleh nilai impedansinya, kemudian membandingkannya dengan nilai setting impedansi tertentu dari rele jarak tersebut [3].

Pemilihan Zone Pengaman pada Rele Jarak. Setting rele jarak berdasarkan pada zone dari saluran transmisi yang diproteksi. Zoneini menggambarkan seberapa panjang saluran yang diproteksi oleh pengaman jarak. Rele jarak dapat diterapkan pada beberapa daerah (zone) dengan waktu yang bisa diatur sesuai keinginan, dengan demikian bisa didapatkan pasangan pengaman utama dan pengaman cadangan sekaligus dalam satu rele jarak.

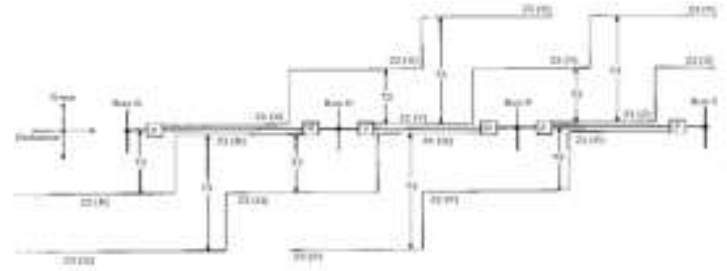

Gambar 2 Daerah penyetelan rele jarak.[4].

Jangkauan Zone 1. Jangkauanini harus mencakup daerah sejauh mungkin dari saluran yang diamankan tetapi tidak boleh melampaui saluran yang ada didepannya. Waktu kerja rele untuk zone-1 adalah seketika $Z 1$ pri $=0,8 \times Z L A$

Jangkauan Zone 2.Jangkauan ini harus pasti dapat menjangkau sisa saluran yang tidak dapat diamankan zone-1 (harus mencapai near end bus), tetapi tidak boleh melebihi (overlap) dengan zone-2 seksi berikutnya. Waktu kerja rele t2 $=0,4$ sampai dengan 0,8 detik.

$Z 2 \min =1,2 \times Z L A$

$Z 2 \max =0,8(Z L 1+0,8 Z L B)$

$Z 2 T=0,8(Z L A+0,5 . X t B)$

Jangkauan Zone 3. Jangkauan ini diusahakan dapat meliputi seluruh saluran seksi berikutnya, (harus mencapai far end bus terpanjang). Waktu kerja rele $\mathrm{t} 3=1,2$ sampai dengan 1,6 detik.

$Z 3 \min =1,2(Z L A+K I . Z L B)$

$Z 3 \max 1=0,8(Z L A+(1,2 \cdot K I \cdot Z L B)$

$Z 3 \max 2=0,8(Z L A+(0,8 \cdot K I \cdot(Z L B+$

$0,8 . Z L C)))$

$Z 3 T=0,8(Z L A+0,8 . X t B)$

Keterangan :

ZLA = impedansi penghantar yang diproteksi.

ZLB = impedansi penghantar berikutnya yang terkecil.

ZLC=impedansi penghantar berikutnya yang terbesar.

$X t B=$ Impedansi Trafo tenaga di GI-B.

$$
\mathrm{KI}=\text { Faktor infeed }
$$

Konfigurasl Jaringan Dan Pengaruh Infeed. Infeed merupakan fenomena penambahan atau pengurangan arus yang melalui suatu titik yang tidak dirasakan oleh rele. Infeed current akan mempengaruhi besaran impedansi yang dideteksi oleh rele sehingga seolah-olah menjadi lebih besar atau sebaliknya menjadi lebih kecil. Faktor infeed ini akan berpengaruh pada penentuan setting jangkauan impedansi pada zone 3 [2]. 
1. Adanya pembangkit pada ujung saluran yang diamankan

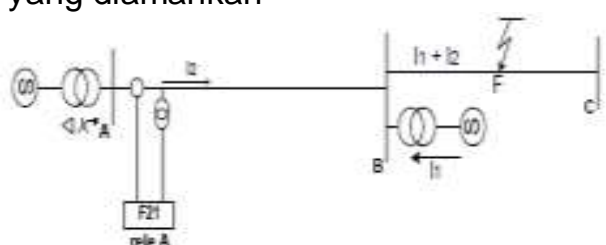

Gambar 3 Adanya pembangkit diujung saluran

Faktor infeedKI $=\frac{\left(I_{1}+I_{2}\right)}{I_{2}}$

2. Adanya perubahan dari saluran transmisi ganda ke tunggal

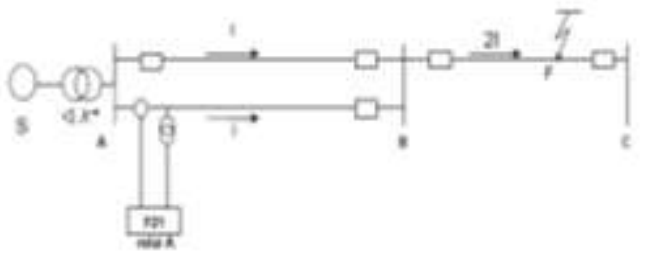

Gambar 4 Saluran ganda ke tunggal

Faktor infeed, $K I=2$

3. Saluran Transmisi Ganda ke Ganda.

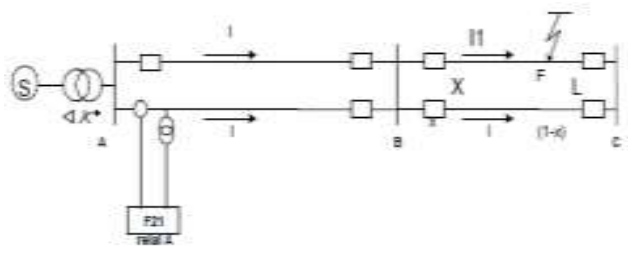

Gambar 5 Saluran ganda ke ganda

Faktor infeed, $K I=\frac{(2 L-X)}{L}$

4. Saluran transmisi tunggal ke ganda

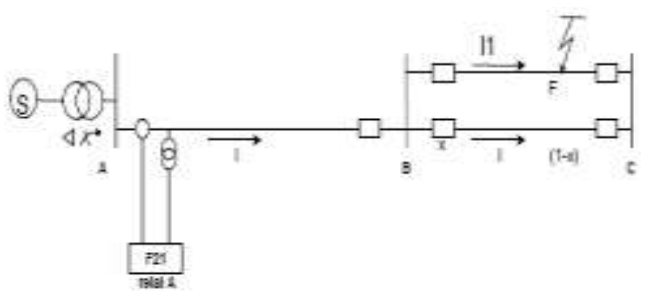

Gambar 6 Saluran tunggal ke ganda

Faktor infeed $K I=\frac{(2 L-X)}{2 L}$

\section{METODE PENELITIAN}

Penelitian ini dilakukan untuk menentukan nilai setting rele jarak agar terjadi koordinasi proteksi pada SUTT $150 \mathrm{kV} \mathrm{GI}$ Ampenan - PLTU LED dalam sistem kelistrikan Lombok.
Data Penelitian. Sumber data penelitian ini menggunakan data sekunder yang diperoleh dari PT. PLN (Persero) UP3B Mataram, meliputi data sebagai berikut:

1. Data saluran udara tegangan tinggi (SUTT) 150 kV sistem kelistrikkan Lombok.

- Jenis konduktor atau penghantar.

- Kapasitas hantar arus (KHA).

- Panjang saluran transmisi.

- Impedansi saluran.

2. Data peralatan proteksi:

- CT dan PT.

- Rele proteksi.

- Transformator daya.

3. Data beban dan arus hubung singkat sistem.

4. Data setting eksisting distance relay.

Langkah-langkah dalam penelitian ini dijelaskan dalam diagram alir berikut :

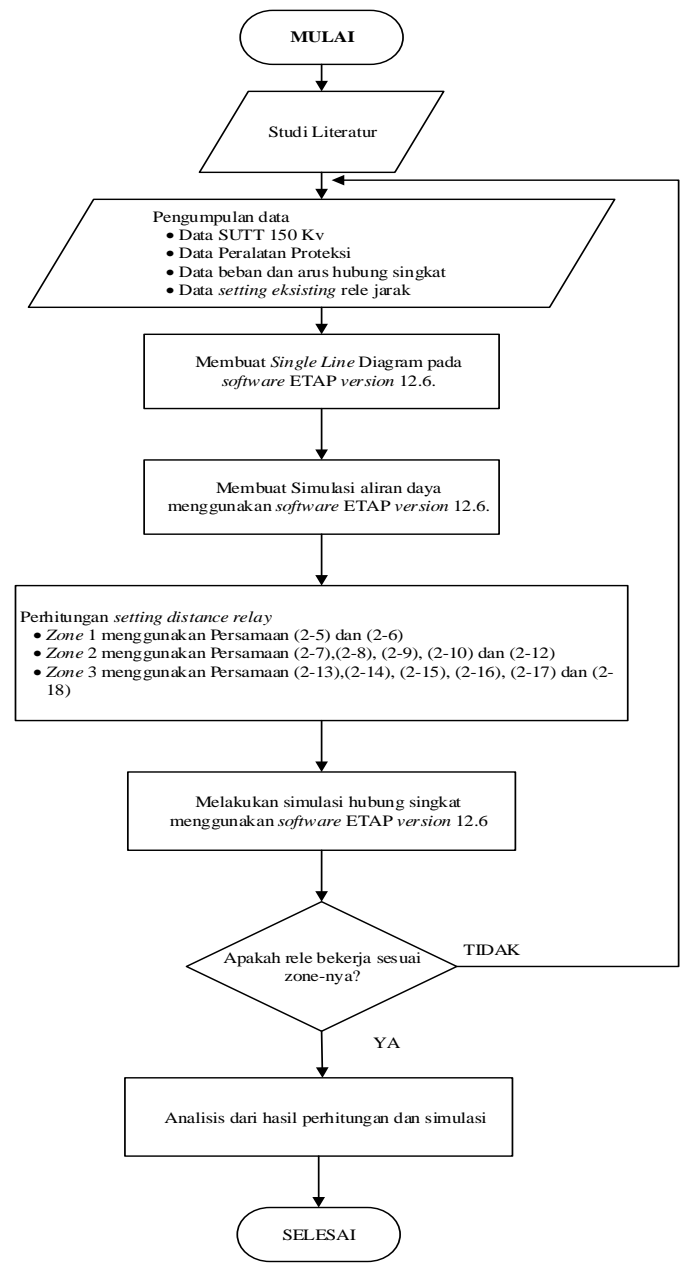

Gambar 7 Diagram alir penelitian [5] 
HASIL DAN PEMBAHASAN

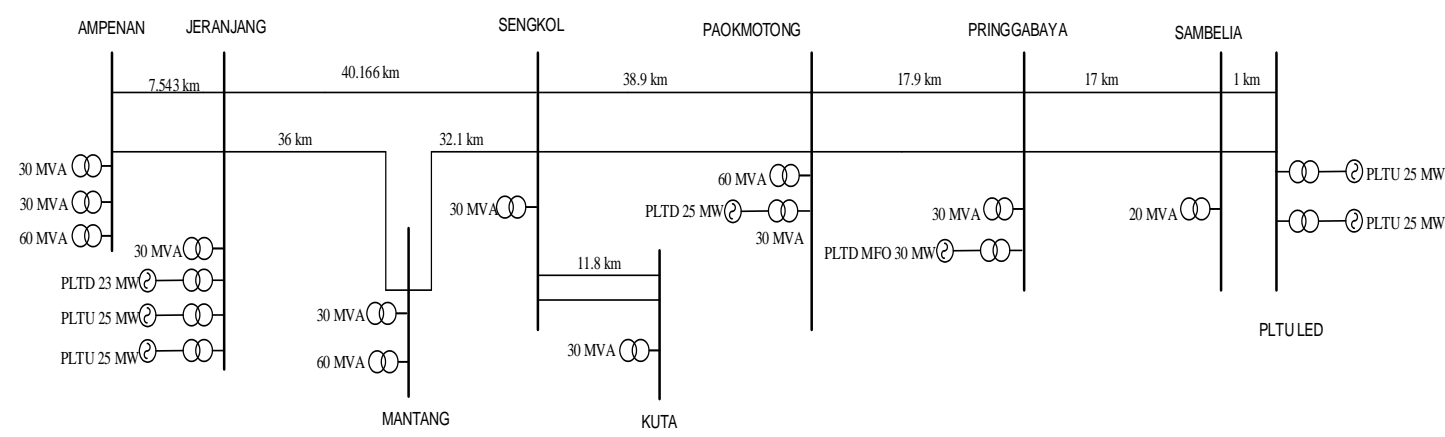

Gambar 8 Diagram satu garis sistem kelistrikan Lombok 150 kV [6]

Perhitungan Setelan Proteksi Rele Jarak.

Tabel 1 Impedansi penghantar saluran udara tegangan tinggi (SUTT) $150 \mathrm{kV}$

\begin{tabular}{cccccc}
\hline No. & SUTT 150 KV & $\begin{array}{c}\text { Panjang } \\
\text { saluran } \\
\mathbf{( k m )}\end{array}$ & Urutan positif & Urutan Negatif & Urutan nol \\
\hline Saluranl. & Jeranjang - & 7.543 & $1.033+\mathrm{j} 3.089$ & $1.033+\mathrm{j} 3.089$ & $2.559+\mathrm{j} 7.108$ \\
\hline & $\begin{array}{c}\text { Ampenan } \\
\text { Jeranjang - } \\
\text { Sengkol }\end{array}$ & 40.166 & $5.503+\mathrm{j} 16.448$ & $5.503+\mathrm{j} 16.448$ & $13.629+\mathrm{j} 37.850$ \\
3 & $\begin{array}{c}\text { Jeranjang - } \\
\text { Mantang }\end{array}$ & 36 & $4.932+\mathrm{j} 14.742$ & $4.932+\mathrm{j} 14.742$ & $12.215+\mathrm{j} 33.923$ \\
4 & $\begin{array}{c}\text { Mantang - } \\
\text { Sengkol }\end{array}$ & 32.1 & $4.397+\mathrm{j} 13.145$ & $4.397+\mathrm{j} 13.145$ & $10.892+\mathrm{j} 30.248$ \\
5 & $\begin{array}{c}\text { Sengkol - } \\
\text { Paokmotong }\end{array}$ & 38.923 & $5.332+\mathrm{j} 15.939$ & $5.332+\mathrm{j} 15.939$ & $13.208+\mathrm{j} 36.676$ \\
6 & $\begin{array}{c}\text { Paokmotong - } \\
\text { Pringgabaya }\end{array}$ & 17.8 & $2.4386+\mathrm{j} 7.289$ & $2.4386+\mathrm{j} 7.289$ & $6.04+\mathrm{j} 16.773$ \\
7 & $\begin{array}{c}\text { Pringgabaya - } \\
\text { Sambelia }\end{array}$ & 17 & $2.3290+\mathrm{j} 6.962$ & $2.3290+\mathrm{j} 6.962$ & $5.768+\mathrm{j} 16.019$ \\
8 & $\begin{array}{c}\text { Sambelia- } \\
\text { PLTU LED }\end{array}$ & 1 & $0.1697+\mathrm{j} 0.4712$ & $0.1697+\mathrm{j} 0.4712$ & $0.0799+\mathrm{j} 0.222$ \\
\hline
\end{tabular}

Rele Jarak $150 \mathrm{kV}$ Ampenan - Jeranjang. Gambar 8 menunjukkan diagram satu garis saluran yang akan diproteksi yaitu saluran Ampenan -Jeranjang.

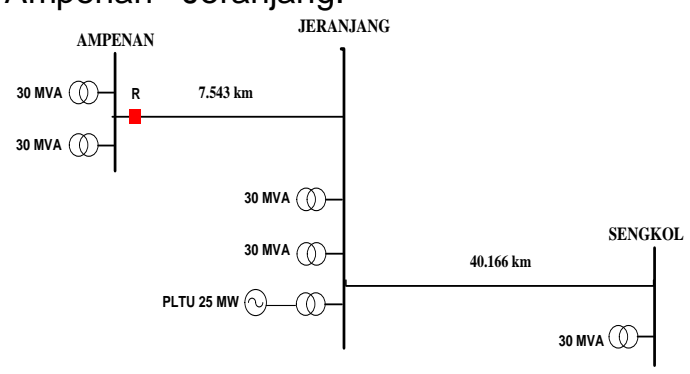

Gambar 9 Diagram satu garis saluran Ampenan Jeranjang

Merek/Tipe Rele : Toshiba/GRZ100-201A

Arus nominal

Lokasi

: $1 \mathrm{~A}$

Proteksi

: Ampenan

: Jeranjang

1. Penghantar yang diproteksi,
$Z L A 1=1,033+j 3,089 \Omega$

$$
Z L A 0=2,559+j 7,108 \Omega
$$

2. Penghantar di depan yang terkecil impedansinya,

$Z L B 1=4,932+j 14,742 \Omega$

$Z L B 0=12,215+j 33,923$

3. Penghantar di depan yang terbesar impedansinya,

$$
\begin{gathered}
Z L C 1=5,503+j 16,448 \Omega \\
Z L C 0=13,629+j 37,850 \Omega
\end{gathered}
$$

\section{Zone-1}

$Z 1$ pri $=0,8 . Z L A 1$

$$
\begin{gathered}
=0,8 \times(1,033+j 3,089) \\
=0,8264+j 2,4712 \Omega \\
Z 1 \text { pri }=2,6057 \measuredangle 71,5^{\circ} \Omega \\
t 1=0 \text { detik }
\end{gathered}
$$


Zone-2

$$
\begin{gathered}
Z 2 \min =1,2 . Z L A 1 \\
=1,2 \times(1,033+j 3,089) \\
=1,2396+j 3,7068 \Omega \\
Z 2 \min =3,9086 \measuredangle 71,5^{\circ} \Omega \\
Z 2 \max =0,8(Z L A 1+0,8 . Z L B 1) \\
=0,8 \times((1,033+j 3,089)+0,8 \\
\times \quad(4,932 \\
+j 14,742)) \\
=4,348+j 12,9979 \Omega \\
Z 2 \max =12,5546 \measuredangle 71,5^{\circ} \Omega
\end{gathered}
$$$$
Z 2 T=0,8(Z L A 1+j 0,5 . X T 1)
$$$$
=0,8 \times((1,033+j 3,089)+j 0,5
$$$$
\times \quad(93))
$$$$
=0,8267+j 39,6711 \Omega
$$$$
|Z 2 T|=39,6797 \Omega
$$$$
Z 2 p r i=1,2396+j 3,7068 \Omega
$$$$
\text { Z2pri }=3,9086 \measuredangle 71,5^{\circ} \Omega
$$

$t 2=0,4$ detik

Zone-3

$$
Z 3 \min =1,2 \times(Z L A 1+Z L B 1)
$$

$Z \_3 \min =22,5627 \measuredangle 71,5^{\circ} \Omega$

$Z 3 \max 1=0,8 \times(Z L A 1+(1,2 \cdot K I . Z L B 1))$

$Z \_3 \max 1=17,5290 \measuredangle 71,5^{\circ} \Omega$

$$
\begin{gathered}
Z 3 \max 2=0,8 \times(Z L A 1+(0,8 \times K I(Z L B 1+ \\
0,8 . Z L C 1))) \\
Z 3 \max 2=21,4347 \measuredangle 71,5^{\circ} \Omega \\
Z 3 T=0,8(Z L A 1+j 0,8 . X T 1) \\
=0,8 \times((1,033+j 3,089)+j 0,8 \\
\times \quad(93)) \\
Z 3 T=61,9966 \measuredangle 71,5^{\circ} \Omega \\
Z 3 p r i=7,1585+j 21,3970 \Omega \\
Z 3 \min =22,5627 \measuredangle 71,5^{\circ} \Omega \\
t=1,2 \text { detik }
\end{gathered}
$$

\begin{tabular}{|c|c|c|c|c|c|c|c|c|c|c|}
\hline \multirow{2}{*}{$\begin{array}{c}\text { Jarak } \\
\text { Gang- } \\
\text { guan } \\
(\%)\end{array}$} & \multirow{2}{*}{$\begin{array}{l}\text { Jenis } \\
\text { Gang- } \\
\text { guan }\end{array}$} & \multicolumn{2}{|c|}{$\begin{array}{c}\mathrm{V}_{\mathrm{f}} \\
\text { (terbaca di GI) }\end{array}$} & \multirow{2}{*}{$\begin{array}{c}\mathbf{I}_{\mathbf{f}} \\
\mathrm{kA}\end{array}$} & \multicolumn{3}{|c|}{$Z_{f}$ primer $(\Omega)$} & \multirow{2}{*}{$\begin{array}{c}\text { Zset. } \\
\text { primer } \\
(\Omega)\end{array}$} & \multirow[t]{2}{*}{ Ket. } & \multirow{2}{*}{$\begin{array}{c}\text { Zone } \\
\text { Opera } \\
\text { te }\end{array}$} \\
\hline & & kV & $\delta$ & & $\delta$ & $\mathbf{\Omega}$ & $\delta$ & & & \\
\hline \multirow[b]{2}{*}{25} & $\begin{array}{l}\text { Tiga } \\
\text { Fasa }\end{array}$ & 1,390 & $-17,1$ & 1,1 & $-85,3$ & 0,7296 & 68,2 & 2.6057 & Operate & $\begin{array}{c}\text { Zone } \\
1\end{array}$ \\
\hline & $\begin{array}{l}\text { Satu } \\
\text { Fasa } \\
\text { Tanah }\end{array}$ & 0,540 & $-15,1$ & 0,739 & -83 & 0,4219 & 67,9 & 2.6057 & Operate & $\begin{array}{c}\text { Zone } \\
1\end{array}$ \\
\hline \multirow[b]{2}{*}{50} & $\begin{array}{l}\text { Tiga } \\
\text { Fasa }\end{array}$ & 2,760 & $-16,9$ & 1,090 & $-85,6$ & 1,4619 & 68,7 & 2.6057 & Operate & $\begin{array}{c}\text { Zone } \\
1\end{array}$ \\
\hline & $\begin{array}{l}\text { Satu } \\
\text { Fasa } \\
\text { Tanah }\end{array}$ & 1,110 & $-15,3$ & 0,718 & $-83,9$ & 0,8926 & 68,6 & 2.6057 & Operate & $\begin{array}{c}\text { Zone } \\
1\end{array}$ \\
\hline \multirow[b]{2}{*}{75} & $\begin{array}{l}\text { Tiga } \\
\text { Fasa }\end{array}$ & 4,100 & $-16,7$ & 1,060 & -86 & 2,2331 & 69,3 & 2.6057 & Operate & $\begin{array}{c}\text { Zone } \\
1\end{array}$ \\
\hline & $\begin{array}{c}\text { Satu } \\
\text { Fasa } \\
\text { Tanah }\end{array}$ & 2,730 & $-15,9$ & 0,712 & $-84,9$ & 2,2137 & 69,0 & 2.6057 & Operate & $\begin{array}{c}\text { Zone } \\
1\end{array}$ \\
\hline \multirow[b]{2}{*}{100} & $\begin{array}{l}\text { Tiga } \\
\text { Fasa }\end{array}$ & 5,420 & $-16,6$ & 1,046 & $-86,6$ & 2,9916 & 70,0 & 3,9086 & Operate & $\begin{array}{c}\text { Zone } \\
2\end{array}$ \\
\hline & $\begin{array}{l}\text { Satu } \\
\text { Fasa } \\
\text { Tanah }\end{array}$ & 3,400 & $-16,7$ & 0,602 & -86 & 3,2608 & 69.3 & 3,9086 & Operate & $\begin{array}{c}\text { Zone } \\
2\end{array}$ \\
\hline
\end{tabular}

Tabel 2 Setting distance relay Ampenan Jeranjang

\begin{tabular}{cccc}
\hline Zone & zone 1 & zone 2 & zone3 \\
\hline $\begin{array}{c}\text { Impedansi } \\
\text { primer }(\Omega)\end{array}$ & 2,6057 & 3,9086 & 22,5627 \\
$\begin{array}{c}\text { Setelan waktu } \\
\text { (detik) }\end{array}$ & 0 & 0,4 & 1,2 \\
\hline
\end{tabular}

Pengujian Setting Rele Jarak Terhadap Gangguan Hubung Singkat. Dalam melakukan pengujian, dilakukan perbandingan antara impedansi setting rele yang terpasang terhadap impedansi gangguan hubung singkat yang terjadi. Skenario yang dilakukan dengan mensimulasikan gangguan, dengan lokasi gangguan sebesar $25 \%, 50 \%, 75 \%$ dan $100 \%$.

Tabel 3 Perhitungan impedansi dirasakan rele saat gangguan hubung singkat SUTT 150kV Ampenan Jeranjang

Berdasarkan Tabel 3 dilihat bahwa Impedansi setting rele lebih besar dari impedansi gangguan yang terbaca oleh rele sehingga rele jarak sudah dapat melindungi sistem. 
Tabel 4 Hasil perhitungan setting rele jarak pada SUTT 150 kV sistem kelistrikan Lombok

\begin{tabular}{|c|c|c|c|c|c|c|c|c|}
\hline \multirow[b]{2}{*}{ No. } & \multicolumn{2}{|c|}{ Saluran } & \multicolumn{2}{|c|}{ Zone 1} & \multicolumn{2}{|c|}{ Zone 2} & \multicolumn{2}{|c|}{ Zone 3} \\
\hline & Dari & $\mathrm{Ke}$ & $\begin{array}{c}\text { Zprimer } \\
(\Omega)\end{array}$ & $\begin{array}{c}\text { td } \\
\text { (detik) }\end{array}$ & $\begin{array}{c}\text { Zprimer } \\
(\Omega)\end{array}$ & $\begin{array}{c}\text { td } \\
\text { (detik) }\end{array}$ & $\begin{array}{c}\text { Zprimer } \\
(\Omega)\end{array}$ & $\begin{array}{c}\text { td } \\
\text { (detik) }\end{array}$ \\
\hline 1 & Jeranjang & Ampenan & 2,6057 & 0 & 3,9086 & 0,4 & 7,8171 & 1,2 \\
\hline 2 & Ampenan & Jeranjang & 2,6057 & 0 & 3,9086 & 0,4 & 22,5627 & 1,2 \\
\hline 3 & Jeranjang & Sengkol & 13,8752 & 0 & 20,8129 & 0,4 & 33,7730 & 1,2 \\
\hline 4 & Sengkol & Jeranjang & 13,8752 & 0 & 20,8129 & 0,4 & 24,7214 & 1,2 \\
\hline 5 & Jeranjang & Mantang & 12,4361 & 0 & 21,3072 & 0,4 & 35,2875 & 1,2 \\
\hline 6 & Mantang & Jeranjang & 12,4361 & 0 & 18,6542 & 0,4 & 22,5627 & 1,2 \\
\hline 7 & Mantang & Sengkol & 11,0889 & 0 & 16,6333 & 0,4 & 27,2239 & 1,2 \\
\hline 8 & Sengkol & Mantang & 11,0889 & 0 & 16,6333 & 0,4 & 33,4643 & 1,2 \\
\hline 9 & Sengkol & Paokmotong & 13,4458 & 0 & 20,1688 & 0,4 & 29,3922 & 1,2 \\
\hline 10 & Paokmotong & Sengkol & 13,4458 & 0 & 20,1688 & 0,4 & 36,8021 & 1,2 \\
\hline 11 & Paokmotong & Pringgabaya & 5,7211 & 0 & 9,2234 & 0,4 & 18,0324 & 1,2 \\
\hline 12 & Pringgabaya & Paokmotong & 6,1490 & 0 & 9,2234 & 0,4 & 29,3922 & 1,2 \\
\hline 13 & Pringgabaya & Sambelia & 5,8726 & 0 & 6,1930 & 0,4 & 9,4097 & 1,2 \\
\hline 14 & Sambelia & Pringgabaya & 5,8726 & 0 & 8,8089 & 0,4 & 18,0324 & 1,2 \\
\hline 15 & Sambelia & PLTU LED & 0,4006 & 0 & 0,6010 & 0,4 & 1,209 & 1,2 \\
\hline 16 & PLTU LED & Sambelia & 0,4006 & 0 & 0,6010 & 0,4 & 9,4097 & 1,2 \\
\hline
\end{tabular}

Koordinasi Setelan Rele Jarak. Untuk mengetahui koordinasi setting rele jarak masing-masing saluran, maka kita harus mengetahui grafik setelan rele jarak. Grafik ini tersebut dapat memperlihatkan apakah rele jarak yang terpasang mengalami overlapping (rele bekerja dalam waktu bersamaan) antar menggambarkan koordinasi antara jangkauan impedansi dan waktu. Grafik setelan rele jarak

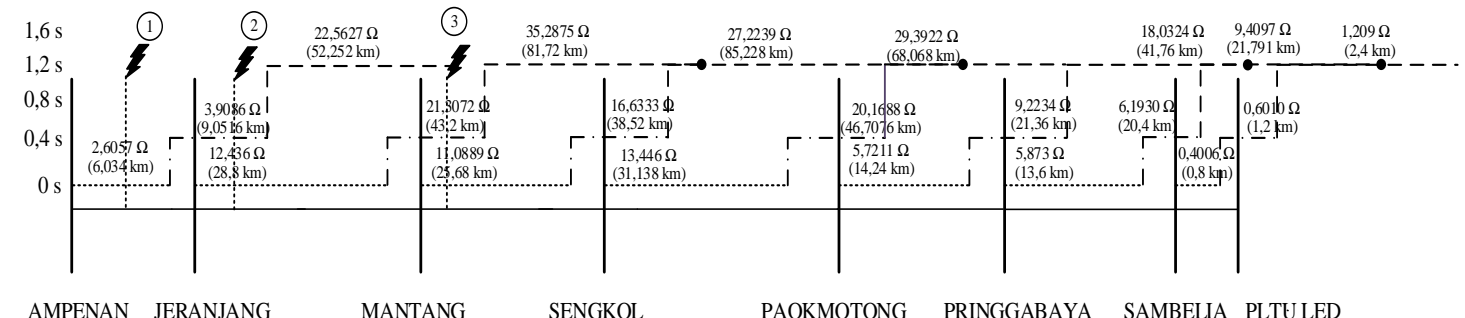

$\begin{array}{lllll}\text { AMPENAN JERANJANG } & \text { MANTANG SENGKOL } & \text { PAOKMOTONG } & \text { PRINGGABAYA } & \text { SAMBELA PLTU LED }\end{array}$

\begin{tabular}{|c|c|c|c|c|c|}
\hline $\begin{array}{c}3,2571 \Omega \\
(7,543 \mathrm{~km})\end{array}$ & $\begin{array}{c}15.5451 \Omega \\
(36 \mathrm{~km})\end{array}$ & $\begin{array}{l}3,2571 \Omega \\
(32,1 \mathrm{~km})\end{array}$ & $\begin{array}{c}15.939 \Omega \\
(38,923 \mathrm{~km})\end{array}$ & $\begin{array}{l}7.686 \Omega \\
(17,8 \mathrm{~km})\end{array}$ & $\begin{array}{r}15.939 \Omega \\
(17 \mathrm{~km})\end{array}$ \\
\hline
\end{tabular}

Keterangan :

.............. : Jangkauan impedansi zone 1

- - . - : : Jangkauan impedansi zone 2

- - - - : : Jangkauan impedansi zone 3

Gambar 10 Koordinasi zone proteksi rele jarak saat gangguan.

Gambar 10 memperlihatkan grafik koordinasi rele jarak saat terjadi gangguan. Pada kondisi nomor 1 saat gangguan di $50 \%$ saluran Ampenan Jeranjang, rele yang bekerja adalah rele di Ampenan daerah proteksi zone satu tanpa waktu tunda (instantaneous). Pada kondisi nomor 2 saat gangguan di $25 \%$ saluran Jeranjang - Mantang, rele yang bekerja adalah rele di Jeranjang daerah proteksi zone satu tanpa waktu tunda (instantaneous). Jika rele jarak tersebut gagal bekerja, maka rele yang akan bekerja adalah rele di Ampenan daerah proteksi zone dua dengan waktu 0,4 detik. Pada kondisi nomor 3 saat gangguan di $25 \%$ saluran Mantang - Sengkol, rele yang bekerja adalah rele di Mantang daerah proteksi zone satu tanpa waktu tunda (instantaneous). Jika rele jarak tersebut gagal bekerja, maka rele yang akan bekerja adalah rele di Jeranjang daerah proteksi zone dua dengan waktu 0,4 detik. Apabila rele tersebut mengalami kegagalan, maka rele yang bekerja 
adalah rele di Ampenan daerah proteksi zone tiga dengan waktu 1,2 detik.

\section{KESIMPULAN}

Hasil perhitungan setting rele jarak di Ampenan untuk memproteksi saluran Ampenan - Jeranjang dengan impedansi saluran $3,25714 \Omega$ dapat di setting dengan Z1pri= 2,6057 $\Omega(6,034 \mathrm{~km}), \mathrm{t} 1=$ 0 detik; Z2pri $=3,9086 \Omega(9,0516 \mathrm{~km})$, t2 $=0,4$ detik; Z3pri $=22,5627 \Omega(52,25 \mathrm{~km})$, t3 $=1,2$ detik. Sedangkan koordinasi diantara rele jarak telah sesuai yang diharapkan karena tidak terjadi overlap antara zone yang diproteksi. Zone satu bekerja tanpa waktu tunda (instantaneous), zone dua bekerja dengan waktu tunda 0,4 detik dan zone tiga bekerja dengan waktu tunda 1,2 detik.

\section{REFERENSI}

[1] Supriyatna, 2014, Proteksi Sistem Tenaga Listrik, Bahan Ajar, Jurusan Teknik Elektro Universitas Mataram.

[2] Tim Dikpro Proteksi, 2010, Materi Diklat Proteksi, Pusat Pendidikan \& pelatihan PT. PLN (Persero).

[3] Tobing, Cristof N.H., 2008, Rele Jarak Sebagai Proteksi Saluran Transmisi, Artikel Ilmiah, Departemen Teknik Elektro Fakultas Teknik Universitas Indonesia.

[4] Elmore. W.A., 1994, Protective Relaying Theory and Applications, ABB Power T\&D Company Inc. Relay Division Coral

[5] Wahyuningsih, R. A., Supriyatna, Muljono, A.B., 2020, Proteksi Rele Jarak (Distance Relay) pada Saluran Udara Tegangan Tinggi (SUTT) 150 kV Sistem Kelistrikan Lombok, Dielektrika Vol. 7 No. 1 hal. 15-24

[6] Tim APDP Mataram., 2018, Single Line $150 \mathrm{kV}$ Sistem Lombok. Area Pengatur Distribusi dan Penyaluran (APDP) Mataram. 